\title{
A psicologia do relacionamento amoroso
}

Ana Lúcia Stipp Paterniani*

$\mathrm{O}$ interesse em estudar os aspectos psicológicos que permeiam as relações amorosas vem da verificação de que há pouco sobre o assunto em termos de literatura científica. Existem muitos trabalhos sobre a resposta sexual orgânica mas poucos enfocando a resposta sexual como experiência subjetiva. Essa abordagem biológica é insuficiente para o entendimento da sexualidade humana." A sexualidade realiza-se na corporeidade em completa sintonia com o psiquismo" (Caridade, 1995).

Poetas e filósofos há muito escrevem sobre o amor. Mais recentemente sociólogos e psicólogos têm demonstrado interesse em procurar respostas e algumas questões intrigantes. Os aspectos psicológicos seriam fatores importantes da experiência sexual? Explicariam como se dá a seleção do parceiro sexual e a intensidade do desejo sexual de cada um? Seriam possivelmente causas de sucesso ou fracasso de um relacionamento amoroso?

Turkenicz (1995), psicanalista, considera a relação de casal um "concentrado de vida psíquica" e portanto um espaço privilegiado para o estudo das experiências amorosas, do ponto de vista psicológico.

1. Médica. Psiquiatra. Pós-graduanda do Curso de Pós-Graduação em Educução Sexual da SBRASH.

Recebido em 26.06.95 
Outro estudioso do assunto. Kernberg (1995), psicanalista, defende a idéia que as raízes psicológicas para entender a sexualidade do casal estariam nas primeiras experiências de sexualidade na infância. $\mathrm{O}$ autor atribui a escassa literatura sobre esse assunto ao "tabu", lembrando que os escritos de Freud foram proscritos na sua época por ousarem reconhecer a existência da sexualidade infantil. Kernberg acredita que os casais tendem a reencenar experiências passadas movidos por fantasias inconscientes projetadas no parceiro.

Outro aspecto que esse autor salienta é a importância dos componentes agressivos (sadomasoquistas) presentes em todas as relações humanas. Kernberg acredita que numa relação amorosa sexualmente madura o casal possa integrar e neutralizar esses aspectos agressivos, incorporando-os à sua atividade erótica. Tal prática tornaria ainda mais rico e Saudável o relacionamento desses casais.

Consideramos interessante a abordagem de Kernberg que desenvolveu a sua teoria baseando-se na sua prática psicanalítica. Passaremos então a discutir as suas idéias de forma mais detalhada e didática, procurando incluir também a opinião de outros autores e a nossa própria.

"Mas seres humanos não são mercadorias, nem objetos para serem comprados, trocados de comprador de uma hora para outra. São pessoas que sentem desejo, curiosidade, solidão, fome de prazer, de amor e a relação sexual permite a manifestação dessas emoções. Acontece que conexões eróticas existem de todos os tipos. Algumas perfeitas (quando a relação é boa, ela é quase indescritível), outras quase perfeitas, outras imperfeitas ou mais que imperfeitas. $O$ importante é compreender a diferença, e quem já viveu sabe, quando se ama, se quer morar dentro do outro. Quando se transa se está de passagem.

(Maria Helena Matarazzo)

\section{Determinantes e Constituintes da Experiência Sexual}

\section{1.l. Identidade de gênero nuclear}

É o sentimento do indivíduo de ser homem ou mulher, determinado pelo gênero a ele atribuído por seus cuidadores, na fase dos 2 aos 4 anos de 
idade. Observa-se que os pais, particularmente a mãe, apresentam diferenças no tratamento com seus bebês, dependendo do gênero atribuído a estes.

As coisas ficarão mais positivas e significativas se a criança for desejada a puder ser benvinda ao Mundo. São essas relações primeiras que vão estruturar o emocional do futuro adulto (Caridade, 1995).

As experiências afetivas entre o bebê e a mãe, quer sejam prazerosas ou dolorosas, são determinantes importantes do desenvolvimento sexual da criança. A falta de cuidados corporais ternos com o bebê, abuso físico ou sexual, experiências vivenciadas como traumáticas e repressão das manifestações sexuais e agressivas da criança, podem vir a inibir ou empobrecer a sua resposta sexual futuramente.

Os estímulos orais proporcionados pela amamentação e o treinamento esfincteriano também são exemplos de situações que conforme forem vivenciadas trarão conseqüências à vivência sexual do adulto, uma vivência dessas situações de forma tranqüila e prazerosa colaborará para uma sexualidade madura. Experiências dolorosas, raivosas e frustrantes poderão bloquear a empobrecer a resposta sexual no adulto.

"Não me arrependo do que fui outrora.

Porque ainda o sou. “

(Fernando Pessoa)

\subsection{Identidade de papel de gênero}

É a identificação do indivíduo com certos comportamentos típicos em hornens ou mulheres numa dada sociedade. Algumas dessas diferenças são bem estabelecidas. Observamos que a mulher apresenta uma maior capacidade verbal do que o homem. por sua vez o homem parece ter uma maior aptidão para a matemática e uma maior tendência à agressividade. Resta saber se essas diferenças são genética ou socialmente determinadas ou ainda uma mistura de ambas. Mas sabemos que elas podem gerar impasse num relacionamento de casal se não houver possibilidade de negociação e diálogo.

Num relacionamento maduro tais diferenças não são encaradas como defeitos e são até mesmo bem vindas por serem ingredientes que colaboram com o enriquecimento da relação. 


\subsection{Seleção do objeto sexual}

Kernberg (1995) acredita que o alvo do desejo sexual também é fortemente influenciado pelas experiências infantis. $\mathrm{O}$ autor propõe que a identificação da criança com o genitor do mesmo gênero possa influenciar de forma a desenvolver um interesse sexual semelhante, no caso, heterossexual. Mas pode acontecer também que a criança possa ter uma identificação predominante com o genitor de gênero oposto ao seu, passando e desenvolver portanto um interesse homossexual.

Essa possibilidade de identificação bissexual da criança poderá se refletir na escolha do parceiro sexual quando adulta.

\section{Intensidade de desejo sexual}

Esta variável também estaria ligada, segundo Kernberg (1995) a lembranças de experiências que ficaram registradas na memória. As fantasias sexuais ligadas a emoções inconscientes seriam um termômetro regulador da intensidade do desejo sexual.

"O que me dói não é

O que há no coração

Mas essas coisas lindas

Que nunca existirão...

São as formas sem forma

Que passam sem que a dor

As possa conhecer

Ou as sonhar o amor".

(Fernando Pessoa)

\section{Excitação Sexual, Desejo Erótico e Amor Sexual Maduro}

\subsection{Excitação sexual}

"O sexo entrou muito cedo em minha vida

Entrou e saiu. Entrou e saiu. Entrou e saiu... e assim sucessivamente"

(Agamenon Mendes Pedreira, jornalista) 
A excitação sexual não se desenvolve tão cedo como a raiva, alegria, tristeza, surpresa e nojo. Assemelha-se a afetos mais complexos como orgulho, vergonha, culpa e desprezo.

Origina-se no contexto das experiências prazerosas dos primeiros relacionamentos intra-familiares, do bebê com os seus cuidadores, na fase do primeiro ao secgundo ano de vida.

É de característica difusa e na maior parte das vezes vinculada à estimulação das zonas erógenas.

"O sangue corre pelas veias e vai direto ao coração. Este contrai, pulsa. Pulsão. Os corpos cavernosos se enchem de sangue, a vagina se contrai, o pénis pulsa. Pulsão.

Estabelece-se o processo de difrenciação originado da fusão do masculino com o feminino.

A diferenciação por sua vez, dá origem à identidade do homem, the permitirá amar, reconhecer, respeitar duas pessoas distintas.

O sexo é a energia que corre através do sangue pelas veias do homem e vai direto ao coração.

(Luiz Carlos Olmedo Freind, psicanalista)

\subsection{Desejo Erótico}

A excitação sexual se transforma em desejo erótico quando sobrevém o desejo de um foco específico para a atividade sexual. Existe um desejo de relacionamento com outro corpo ou com um símbolo que represente esse corpo (fetichismo).

A expressão do desejo erótico pode se dar de forma afetuosa, terna, perversa ou sadomasoquista. Essas variações podem estar associadas às experiências infantis do bebê com seus cuidadores, como temos vistos.

A busca de prazer, o anseio de proximidade, a fusão e entrelaçamento podem estar ligadas às fantasias sexuais conscientes e inconscientes de invasão, penetração e apropriação. O corpo com as suas cavidades e protuberâncias parece buscar o encaixe complementar para a gratificação erótica. Essa sensação de fusão e complementaridade remete às fantasias de bissexualidade da infância. Temporariamente as diferenças de gênero se neutralizam gerando um sentimento de completude e satisfação. 
O desejo erótico inclui também um sentimento de transgressão, de se poder por um momento superar as proibições e repressões sociais. A nudez pode simbolizar essa transgressão temporária às normas sociais.

Os componentes agressivos também caracterizam o desejo erótico, variando na forma e intensidade para cada pessoa. $\mathrm{O}$ desejo de produzir dor no outro a identificar-se com o prazer erótico do outro caracteriza o sadismo erótico. Já o masoquismo erótico aparece quando existe um elemento de rendição, de aceitação de ser objeto da dor induzida pelo outro. O masoquista identifica-se também com o seu agressor, sentindo-se ao mesmo tempo escravo e senhor.

Em resumo, tanto no prazer como na dor está a busca de uma experiência afetiva intensa.

"Para quem o prazer é prazer e o recreio é recreio,

Que dorme sono,

Que come comida

Que bebe bebida, e por isso tem alegria.

A calma que tinhas, deste-me e foi-me inquietação.

Libertaste-me, mas o destino humano é ser escravo.

Acordaste-me, mas o sentido de ser humano é dormir."

(Fernando Pessoa)

\subsection{O amor sexual maduro}

O amor sexual maduro é uma disposição emocional complexa. Ocorre quando a excitação sexual se transforma em desejo erótico por uma outra pessoa. A escolha dessa pessoa é possivelmente determinada em parte por motivações inconscientes ligadas ao passado como vimos. Porém agora também existem expectativas conscientes de uma vida futura como casal. Isso implica num compromisso com a vida do outro, não só na esfera sexual e emocional mas também em relação a valores e ideais. Esse conceito de amor sexual maduro dado por Kernberg (1995) me Parece semelhante ao que Matarazzo (1992) chama de casamento aberto em seu livro "Amar é Preciso". Caracteriza esse tipo de relacionamento o compartilhar de intimidades nos setores intelectual, emocional, social e sexual. A qualidade do vínculo pode ser medida pelo nível de trocas que o casal tem capacidade para estabelecer. 
A busca do companherismo e do convívio harmonioso é um empreendimento que leva tempo e muita dedicação, mas a gratificação de alcançar esse objetivo é a recompensa para o casal. O psicanalista Turkeniecz (1995) também ressalta a importância da solidariedade e cumplicidade como ingredientes importantes para as alegrias da vida em comum.

Se compararmos o amor sexual maduro a um arco-íris e tentarmos através de um prisma imaginário identificar o espectro dos sentimentos que o caracterizam, talvez encontrássemos os descritos a seguir:

\subsubsection{Tolerância}

Kernberg (1995) chama a atenção para a importância da tolerância com os aspectos agressivos (sadomasoquistas) da relação. Na sua observação, num relacionamento amoroso maduro existe um conluio implícito entre os parceiros. Estes tentam identificar e procuram atender as necessidades passivas, ativas, sádicas/masoquistas do companheiro. Pare isso é necessário que haja compreensão e tolerância para com os desejos fantasiados e reais do outro. A empatia, confiança e respeito fazem com que os parceiros possam ser tratados como "puros objetos sexuais" conforme suas necessidades sem que isso denote falta de amor. Ao contrário, quando o amor predomina, ele triunfa e neutraliza esses aspectos agressivos reforçando a união do casal.

Essa agressão a serviço do amor garante que a relação adquira profundidade e significado e os parceiros podem compartilhar então momentos de mútua contemplação tranqüila, paz e serenidade.

É claro que essas expressões polimorfas da sexualidade que incorporam o amor e o ódio na atividade erótica (fantasias e desejos voyeristas/exibicionistas, sadomasoquistas, etc.) também podem ameaçar a relação e até gerar um rompimento.

Só mesmo um profundo comprometimento com o outro, que transcende a relação sexual e atinge valores comuns a uma vida compartilhada pode proteger e garantir a estabilidade de um relacionamento.

\subsubsection{Ternura}

Kernberg (1995) considera a ternura outro sentimento que caracteriza o amor sexual maduro. Define esse estado como sendo a capacidade de se preocupar, de ter cuidado e compaixão para com a pessoa amada. 
"E posso te dizer que o grande afeto que te deixo

Não traz o exaspero das lágrimas nem a fascinação das promessas Nem as misteriosas palavras dos véus da alma...

É um sossego, uma unção, um transbordamento de carícias..."

(Vinicius de Moraes)

\subsubsection{Identificação}

A identificação com o outro é um estado no qual os interesses, desejos, sentimentos e dificuldades do parceiro estão na mesma sintoma e alcançam o mesmo grau de importância dos nossos próprios.

Matarazzo (1992) e Shinyashiki (1988) concordam que quando há admiração, respeito e confiança as diferenças não são consideradas defeitos e sim uma oportunidade de um ajudar o outro a crescer e ser o melhor de si mesmo.

\subsubsection{Idealização}

A idealização no amor sexual maduro inclui o compromisso com os ideais e valores do companheiro. A aceitação do outro como pessoa total e a admiração fez com que a idealização inicial do corpo do parceiro se integre à idealização de todo um sistema de valores éticos, culturais que incluem os estéticos e de beleza.

"Se eu fora Deus, por ti, ó mulher a quem amo,

Eternameute azuis desdobraria os céus;

Mas a mesma, qual és, meu anjo, eu te deixaria, Se eu fora Deus.

(Sully Prudhomme)

\subsubsection{Paixão}

Kernberg (1995) observou que o caráter apaixonado é outra característica das relações de amor sexual maduro. Acrescenta que a paixão pode estar presente mesmo nas relações de muitos anos. A paixão 
tem a função de proporcionar intensidade para consolidar e renovar as relações amorosas por toda vida, deixando sempre acesa a chama da atração sexual.

Turkenicz (1995) tem opinião semelhante a também interessante a esse respeito. Este psicanalista identifica na sociedade alguns mitos do que é considerado desejável para uma relação de casal. Um desses mitos é de que a moderação e a estabilidade dos sentimentos é o que mantém a harmonia e a felicidade do casal. A crença nesse mito leva as pessoas a desenvolverem uma verdadeira fobia à paixão e aos sentimentos intensos. Isso muitas vezes leva os casas a cronificarem suas relações constituindo arranjos de psicopatologias complementares. Admite que o apaixonamento oferece alguns riscos mas ao mesmo tempo é o que mantém a saúde da relação.

A paixão é tempestade, cíclica e limitada. Amor é brisa, infinito e duradouro se renovando constantemente. Esta é a concepção do psicoterapeuta Shinyashiki (1988) em seu livro "Amar Pode Dar Certo". Assim como Turkenicz (1995) ele também identifica nas pessoas o medo de uma maior intimidade e do apaixonamento o que leva muitas vezes as pessoas a permanecerem numa relação insatisfatória por comodidade e preguiça.

A paixão aumenta o desejo sexual e mantém a alegria e o prazer dos namorados, mesmo numa relação de muitos anos mas que se permite renovar constantemente.

A sedução, o olhar, o toque físico e a fantasia talvez sejam os segredos dos eternos namorados.

Outro dia uma paciente nos ensinou na sabedoria dos seus 70 anos que uma mulher em qualquer idade precisa de moradia, alimentação e... romance.

“As paixões são como as ventanias

que enfunam as velas dos navios.

Algumas vezes os submergem,

mas sem elas não se poderia navegar. “

(Voltaire)

\subsubsection{Prazer}

O prazer e a sensação de transcendência que acompanha o amor maduro podem ser comparados ao êxtase do religioso com sua fé. 
Shinyashiki (1988) e Matarazzo (1992) concordam quando dizem que conversar, namorar, brincar, compartilhar bons e maus momentos e ter amigos em comum são prazeres significativos de uma relação amorosa.

A qualidade das relações sexuais pode ser um espelho da relação como um todo. O sexo quando feito com quem se ama traz calor, energia, vida, prazer e intimidade. No orgasmo pleno sente-se que há uma fusão do ser com o cosmos levando àquela sensação de êxtase e transcendência. $\mathrm{O}$ orgasmo é mais facilmente conseguido quando há uma relação de total entrega e confiança entre os parceiros. Mas a sua ausência não quer necessariamente dizer que a relação não seja boa porque há outras variáveis que interferem na atividade sexual. O orgasmo aumenta o prazer da relação mas não é condição para uma relação gratificante e significativa. Pode haver períodos de amor com sexo e períodos de amor sem sexo.

"A diferença entre os prazeres espirituais e os materiais reside em, que os materiais engendram o desejo antes de que sejam obtidos e uma vez obtidos se tornam fastio; enquanto os espirituais não suscitam cuidados enquanto não se os alcança e continuarão desejados mesmo quando se os tem alcançado.

(São Gregório)

\subsubsection{Liberdade}

No amor sexual maduro, o sentimento de liberdade vai além dos limites da existência cotidiana.

A questão da fidelidade e sinceridade é uma opção feita pelos parceiros e não implica em coerção.

'A suprema liberdade é poder deixar-se ser possuído pelo sentimento de amor. "

(Roberto Shinyashiki)

\subsubsection{Prazer}

Caridade (1995) também reforça a importância de se manter um espaço de liberdade e individualidade entre os parceiros para que a relação se mantenha saudável, leve e suave. A possessividade é o sentimento sexual mais contraditório ao amor. 
“... É estar-se preso por vontade;

É servir a quem vence o vencedor;

É um ter com quem nos mate lealdade.

Mas como causar pode o seu fervor

Nos mortais corações conformidade

Sendo a si tão contrário o mesmo amor?"

(Luis de Camões)

Como num arco-íris os sentimentos do amor sexual maduro se entrelaçam e se superpõe formando esse todo que é o amor. Mas o que é o amor afinal?

"Amor é, não possuí-lo: amor, vivê-lo.

Possuí-lo é desvendá-lo. E amor-verdade,

beleza, poesia, sarça ardente,

é refratário a toda matemática.

Amor é sol que não se vê mas queima.

Ave, não canta, mas the o canto ouvimos,

- mas de um outro entender, que só de ouvidos

da alma é ouvir cantigas represadas.

Sol e ave. Mas, ave, é um sol que brilha.

Queimar-se dele. Por suprema graça,

ver-lhe do espectro as invisiveis cores.

Jamais situá-lo, em tosca astronomia.

Pesquisá-lo é destruí-lo.

Amor, portanto:

queimar-se, e só, sem mais filosofia."

(Anderson Braga Horta)

\section{Considerações Finais}

Um casal num relacionamento amoroso pleno desafia a eterna inveja dos que se sentem excluídos e compactuam com a cultura convencional na qual convivem. Se o casal pode incorporar suas fantasias desejos perversos polimorfos ao seu relacionamento sexual descobrir e revelar o núcleo sadomasoquista da excitação sexual em sua intimidade, 
seu desafio à cultura convencional pode tornar-se um elemento consciente de seu prazer.

A constatação da finitude de um relacionamento quer seja por término da relação ou pela morte é tanto mais dolorosamente sentida quanto mais profundo e intenso for o relacionamento amoroso. E quando os amantes tomam a consciência disso seu amor fica ainda mais intensificado

Para finalizar, transcrevemos "Parcialidades" de Gerson Noronha Filho, $\mathrm{PhD}$ em medicina sanitária. Em nossa opinião ele conseguiu resumir a conclusão que todos chegamos ao final do estudo desse tema.

"Se medirmos em quilômetros os livros que abordam os benefícios que o sexo pode trazer vamos ter que andar de automóvel por muitos dias. E mesmo lendo toda esta biblioteca você chegará a uma só certeza. ninguém está satisfeito com as respostas existentes. Há sempre nas teorias nos relatos e nas esplicações uma falta um inconforto que nos diz que a palavra final ainda não foi alcançada. Talvez não seja alcançada nunca Coisas da condição humana. Coisas de nossas vidas curtas. As teorias por melhor que sejam são sempre visões parciais nunca atingem o nível de uma esplicação totalizante. Depois da teoria da relatividade até a física se tornou poética e cheia de surpresas. Sem falar na astronamia a nos encabular com hipóteses que mais parece delírios

Não existe pergunta fácil quando se trata de sexo. Para mim, falar em sexo traz sempre à mente aquela definição meio cósmica e meio real de que quando fazemos sexo com alguém vem junto prá cama pelo menos umas seis pessoas. Quer dizer, que além dos dois principais beneneficiados da atividade sexual há uma série de condjurantes ausentes que se beneficia indiretamente do processo. Vem daí beleza e a complicação da matéria Vem daí a dificuldade de fazermos sexo a dois livres do passado e das culpas.

É possivel listar os benefícios do sexo para a saúde. Mas não valem para quem ainda está em aprendizado. Ou tem dificuldades. Ou está em tratamento Ou sofre de inapetência. Ou ainda não encontrou o parceiro/a ideal Ou tem baixa frequência. Ou faz sexo sem amor. Ou ainda não teve a oportunidade de conseguir um orgasmo a dois. Como vocês podem imaginar ser feliz em sexo não é para qualquer um. É coisa rara. É uma tarefa para milênios. Uma tarefa para imortais Todos somos chamados mas pouquíssimos são os escolhidos como vêem trata-se de uma lista de benefícios aplicável para os poucos felizardos que conseguem unir sexo com alta frequência, amor, orgasmo e prazer, nesses casos, observa-se menos somatização, recuperação mais rápida em situações de doença, menos uso da doença (ganho secundário) como forma de atrair a atenção e carinho de parentes ou de profissionais, hábitos alimentares mais saudáveis e vida 
menos sedentária, incidência menor de distúrbios psíquicos, descarga positiva de energia que alivia tensões revitaliza o organismo e favorece um envelhecimento mais gradual, estabilidade afetiva com reflexos na incidência de doenças, além dos efeitos psíquicos do orgasmo (a dois preferencialmente) com tudo que significa de amor, felicidade, alegria, conhecimento e encontro.

Em sexo e amor somos sempre aprendizes. E uma coisa posso dizer: onde lhe há sexo, amor e orgasmo haverá sempre espaço para vírgulas a acrescentar. Daí a graça da matéria. Ainda bem."

\section{REFERÊNCIAS BIBLIOGRÁFICAS}

1. AYAlA, W. Poemas de Amor. Rio de Janeiro, Ediouro, 1991 - pág. 27, Anderson Braga Horta, Amor: pág. 184. Luis de Camões, Poema I: pág. 202, Sully Prudhomme, Se eu fora Deus.

2. CAMARÁ, R. Paixão - Instantes de Refexão (p. 5, Voltaire). São Paulo, Ed. Melhoramentos, 1995.

3. CAMA RA, R. Prayer - Instantes de Reflexão (p. 47, São Gregório). São Paulo, Ed. Melhoramentos, 1995.

4. CARIDADE, A. In: Revista Brasileira de Sexualidade Humana, vol. 6. São Paulo, Ed. Iglu, 1995 - pág. 51. Sexo, reprodução, amor e erotismo.

5. KERNBERG, O. F. Psicopatologia das relações amorosas. Porto Alegre, Ed. Artes Médicas, 1995.

6. LACERDA, L. 131 Posições sexuais. São Paulo, Ed. Best Seller. 1994 - pág. 17, Maria Helena Matarazzo. Conexões eróticas; pág. 30, Gerson Noronha Filho, Parcialidades: pág. 150, Luis Carlos Olmedo Freind, Im-Pulsão; pág. 187. Agamenon Mendes Pedreira, Gracinhas.

7. MATARAZZO. M. H. Amar é Preciso. São Paulo. Ed. Gente, 1992.

8. MORAES. V. Antologia Poética. Rio de Janeiro, Ed. Nova Fronteira, 1985.

9. PESSOA, F. Poemas - Poesias de Todos os Tempos. Rio de Janeiro, Ed. Nova Fronteira, 1985.

10. SHINYASHIKI, R.; DUMET. E. B. Amar pode dar certo. São Paulo, Ed. Gente, 1988.

11. TURKENICZ, A. A aventura do casal. Porto Alegre, Ed. Artes Médicas, 1995. 